\title{
Polyaniline and Polythiophene Modified Electrodes in Energy Storage Units with Hydrocarbon Gel/Bentonite/Sodium Chloride as Electrolyte Gel.
}

\author{
Duke Orata ${ }^{* 1}$, Hellen Njenga ${ }^{2}$, Marina Mukabi ${ }^{3}$, Yusuf Amir ${ }^{4}$, Damaris Mbui ${ }^{5}$ \\ ${ }^{12345}$ Department of Chemistry, P.O. Box 30197-00100, Nairobi., University of Nairobi
}

\begin{abstract}
In this paper we present results obtained for energy storage units developed using polyaniline and polythiophene modified electrodes. The voltage potential profiles for recharge/discharge are either linear or exponential. Nucleation over-potential has been observed in some profiles where there is a phase transition. It is observed that hydrocarbon gel: bentonite electrolyte mixtures yielded relatively high initial voltages and that, this voltage also depended on the hydrocarbon: bentonite ratio. The potential decay profile for potential at Vo, $3 / 4 \mathrm{Vo}, 1 / 2 \mathrm{Vo}$ and $1 / 3 \mathrm{Vo}$ yielded linear and exponential curves for various hydrocarbon:bentonite mixtures. The capacity (C) were $0.0014 \mathrm{Ah}$, for the 2:1 energy unit and 0.00035 Ah for the 3:1 energy unit. The electric storage density (ESD) for the 2:1 and 3:1 energy units were $4.7 \times 10^{-4} \mathrm{Ah} / \mathrm{g}$ and $8.8 \times 10^{-5} \mathrm{Ah} / \mathrm{g}$ Key words: Electronically conducting polymers, Bentonite, Hydrocarbon gel, discharge profile
\end{abstract}

\section{Introduction:}

Research in electronically conducting polymers as continued unabated since the discovery of the highly conducting polyacetylene. The discovery of other electronically conducting polymers such as polyaniline, polypyrrole and polythiophene has even widened the frontiers of research with regards to this conducting 'plastics' (1-12).

These conducting polymers are already being used as electrochromic display devices, components of rechargeable batteries just to mention a few (12-16).

Intense research in the use of these polymers in rechargeable batteries is on-going (17-22). These polymers have drawn much attention given that their specific weight is significantly lower than that of ordinary inorganic materials and they are environment friendly.

Rechargeable batteries are batteries which can be restored after complete discharge. Examples include $\mathrm{Li}$-ion and Ni-MH. These batteries had almost the same energy storage capacity as that of the primary alkaline cell.

Earlier reported studies on the use of conducting polymers in battery studies, is represented by the case where p-doped (oxidized) polyacetylene was used as the cathode and $\mathrm{Li}$ as anode. Ni-Cd batteries had a better energy storing capacity and high performance compared to lead-acid batteries. These Ni-Cd batteries can withstand high current surges and tolerate adverse conditions without any damage. The major disadvantage is that, the negative electrode cadmium is a toxic material, hence not environment friendly.

Lithium ion batteries are commonly used given that, they have a low self-discharge, energy-to-weight ratio and no memory loss.

Research has been on-going in attempts to develop new rechargeable batteries using conjugated conducting polymers. The batteries christened 'plastic batteries' has traditionally involved the polymer material being doped by specific dopant material to convert it to a semi-conductor, with the lithium as one of the electrode in rechargeable battery (16-17).

Batteries with polymer as both the electrodes have been developed. Polypyrrole and styryl-substituted dialkoxyterthiophene (poly (OC10DASTT). The batteries of these combinations showed as high as $94 \%$ discharge efficiency and a discharge capacity of $39.1 \mathrm{mAhg}^{-1}$ (18). Other studies on polymer based batteries have been done by Killian (15).

In this paper we have used polyaniline, and polythiophene modified electrodes in the energy storage unit.

Bentonite a clay montmorillonite which has octahedral $\left(\mathrm{O}_{\mathrm{h}}\right)$ and tetrahedral sites $\left(\mathrm{T}_{\mathrm{d}}\right) /$ layers, with exchangeable cations being found in the octahedral layer has been used, singularly or with hydrocarbon gel/sodium chloride in known ratios (mass/mass). In the energy storage units discussed in this work, the bentonite/hydrocarbon gel/sodium chloride serve both as an electrolyte and/or an electrode i.e., source of dopant ions and a participant in the faradaic process. 


\section{Chemical Reagents:}

\section{Experimental section:}

The monomer liquids used were aniline (Aldrich, 98\%) and thiophene (Aldrich, 99\%). They were triply distilled until colourless liquids were obtained in each case. They were then stored under an inert gas nitrogen. This distillation process was repeated for each fresh experiment. All the chemicals and acids were analytical grade and were used as received without further purification. Two types of acids as supporting electrolyte were used namely sulphuric acid (Gowa), and hydrochloric acid (Gowa). Other chemicals used include potassium chloride (Aldrich), sodium chloride (Aldrich), and hydrocarbon gel (Orbit Chemicals).

All solutions were prepared using high purity solvents. For the aqueous systems, triply distilled water obtained from a Millipore water purification system was used. For the non-aqueous studies, acetonitrile (HPLC grade, Fischer) was used as received.

All weighings were done using an analytical balance for maximum accuracy.

The clay montmorillonite, i.e., bentonite (Athi River Mining Company Ltd., Kenya) was purified as described by Gosh and Bard, 1983, and by Ege et.al., 1985. It has a mesh size ranging from 150 to $200 \mu \mathrm{m}$, cation exchange capacity (CEC) $1.18-1.22 \mathrm{mM} / \mathrm{g}$ and $\mathrm{pH}$ range of $8.4-9.6$. The density of bentonite is 1.25 $\mathrm{g} / \mathrm{cm}^{3}$ which is comparable to other clay minerals from different parts of the world (Rask, 1984). It has average solvent retention capacity of $22.5 \%$ and $4.8 \%$ for water and organic solvents respectively. Its moisture content is $8.5 \%$. It swells by a factor of 1.7 and 1.4 in water and organic solvents respectively.

The preparation of the carbon graphite electrode and the methodology of modifying the carbon graphite electrode surface with bentonite was as described by Orata and Kariuki, 1996. Polyaniline and polythiophene modified electrodes were prepared by cycling the potential of the modified electrode within a given potential window in solution containing aniline/or thiophene monomer with $\mathrm{H}_{2} \mathrm{SO}_{4}$ as the supporting electrolyte.

\section{Energy Storage Unit:}

The design used in the energy storage unit experiments is shown in the Figure 1 below:

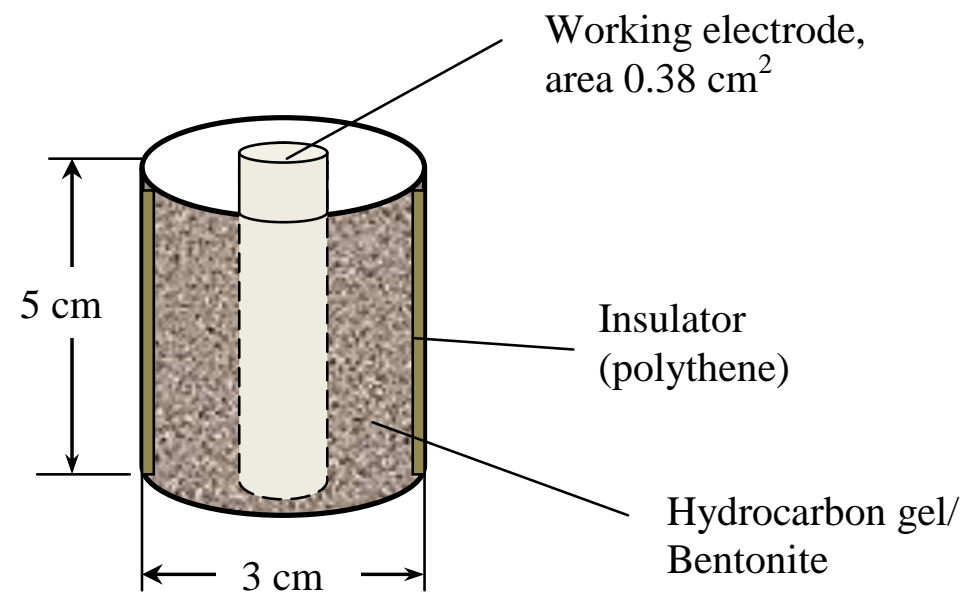

Figure 1: Proto-type used in the energy storage unit experiments.

The circuit used in the discharge/recharge studies consisted of voltmeter and resistors as shown in Figure 2 below.

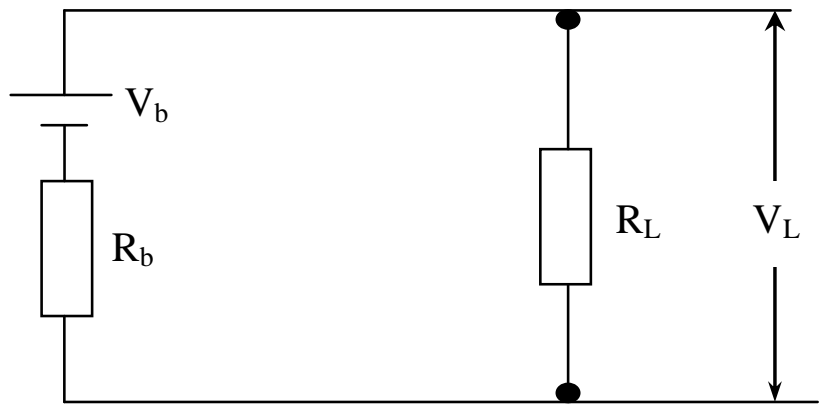

Figure 2: Circuit for study loading.

$\mathrm{V}_{\mathrm{b}}$ - voltage of the battery, measurable at no-load.

$\mathrm{V}_{\mathrm{L}}$ - voltage of the load (usually known)

$\mathrm{R}_{\mathrm{b}}$ - resistance of the battery (is to be computed)

$\mathrm{R}_{\mathrm{L}}$ - resistance of the load (usually known) 


\section{Results and Discussion:}

In this study the conducting polymer used was electro-synthesized by cycling the potential of a carbon graphite working electrode from $-0.2 \mathrm{~V}$ to $0.80 \mathrm{~V}$ in the case of polyaniline, and from $-0.2 \mathrm{~V}$ to $0.86 \mathrm{~V}$ in the case of polythiophene. The scan rate was $20 \mathrm{mV} / \mathrm{sec}$ in both cases. The electrolyte solution contained $0.1 \mathrm{M}$ aniline / or $0.1 \mathrm{M}$ thiophene monomer, and $1 \mathrm{M} \mathrm{H}_{2} \mathrm{SO}_{4}$ as the supporting electrolyte.

In the energy storage devices shown in Figure 1 bare carbon graphite/or conducting polymer modified electrode served as a redox couple.

The working electrode was derivatised with a conducting polymer, the redox process in all the cases were stopped at the oxidized end, where the polymer is oxidized/ or in the conducting state. The conducting polymer modified carbon graphite working electrode was then used in the energy storage unit shown in Figure 1.

The loading of the cell was achieved using the circuit shown in Figure 2.

\section{Bare Carbon and Polyaniline Modified Electrode as a Redox Couple}

Bare carbon graphite working electrode and a polyaniline modified carbon graphite were used as one of the redox couples in the experiment.

In the case of polyaniline several films were electrodeposited as already mentioned. The variation of the oxidative charge versus time was computed. The results are shown Figure 3. It is observed that the oxidative charge increases linearly with time in all the cases studied.

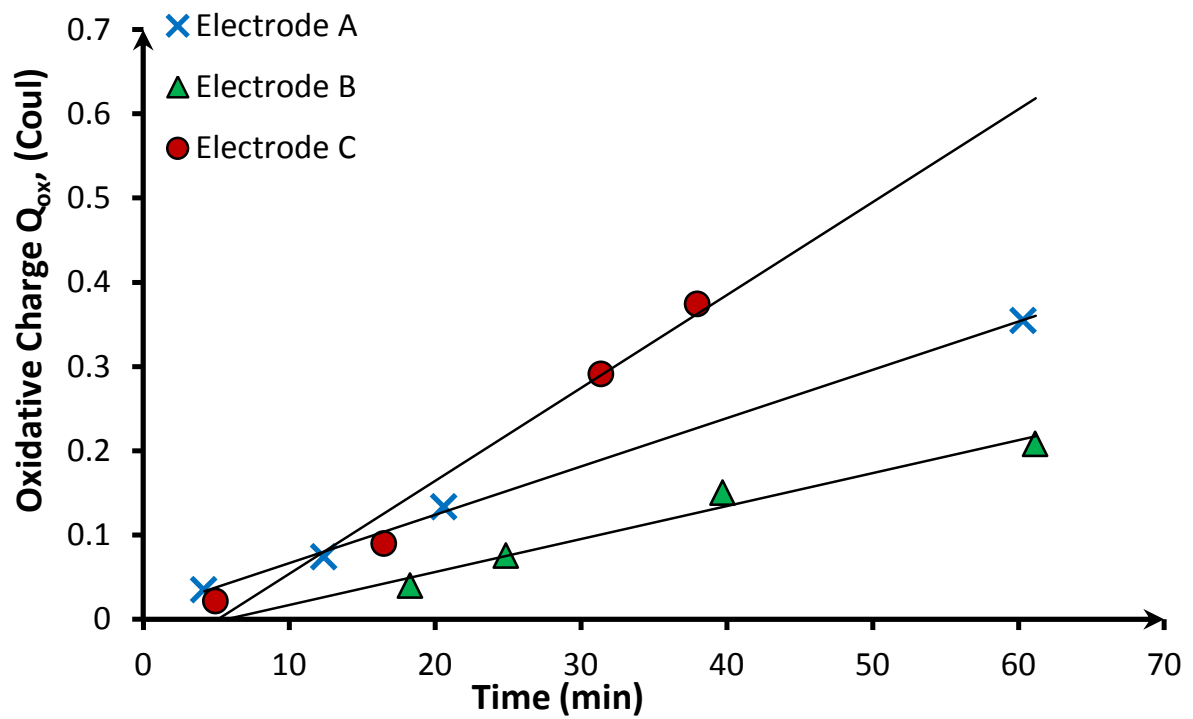

Figure 3: Plot of oxidative charge, $\left(Q_{\text {,ox }}\right)$ versus time for polyaniline electrodeposited on a bare carbon electrode in solution containing $0.1 \mathrm{M}$ aniline and $0.5 \mathrm{M} \mathrm{H}_{2} \mathrm{SO}_{4}$. The potential range was from - 0.2 to $0.80 \mathrm{~V}$. Scan rate $20 \mathrm{mV} / \mathrm{s}$.

The bare carbon graphite and polyaniline modified electrodes were mounted in the different energy units and the potential versus time profiles obtained. The results are shown in Figures 4 and 5.

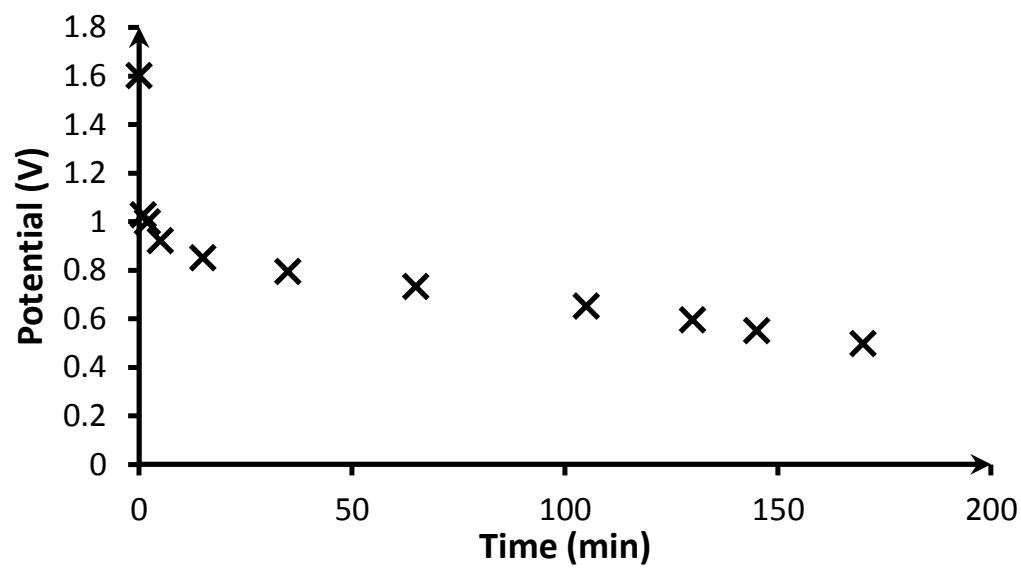

Figure 4: A plot of potential (V) versus time for bare carbon electrode. 


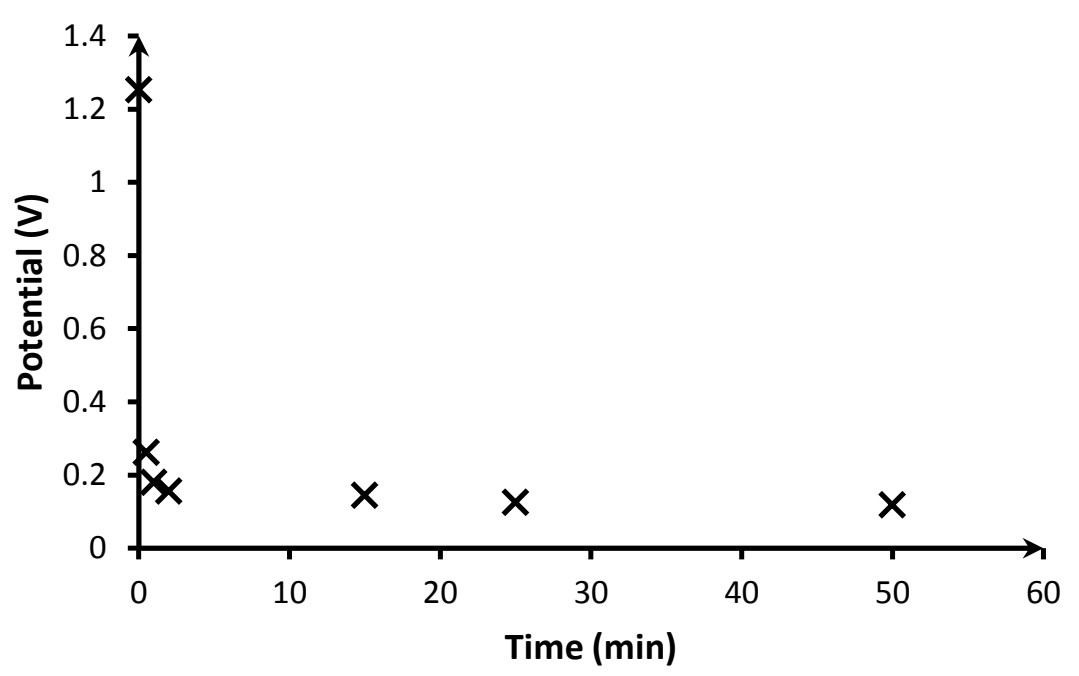

Figure 5: A plot of potential (V) versus time for polyaniline modified carbon electrode in solution containing $0.1 \mathrm{M}$ aniline and $0.5 \mathrm{M} \mathrm{H}_{2} \mathrm{SO}_{4}$.

It is observed that, the initial potential for bare carbon case is much higher $(1.60 \mathrm{~V})$ than that obtained in the case of polyaniline modified electrode $(1.25 \mathrm{~V})$ i.e., $\Delta \mathrm{E}_{\mathrm{i}}=347 \mathrm{mV}$. The initial potential of polyaniline modified electrode is less than that of bare carbon electrode by $22 \%$.

These differences could result from all/or any of the following: free energy change in the overall cell reaction $(\Delta \mathrm{G})$, the cell resistance $(\mathrm{iR})$ and the kinetics of the electrode reactions.

In general,

$$
\left.\mathrm{E}_{\text {cell }}=\mathrm{E}_{\mathrm{C}}-\mathrm{E}_{\mathrm{A}}-\mathrm{n}_{\mathrm{A}}-\mathrm{n}_{\mathrm{C}}-\mathrm{i} \mathrm{R}_{\text {cell }} \ldots \ldots \ldots \ldots \ldots \ldots \ldots \ldots \ldots \ldots \ldots \text { (Equation } 1\right)
$$

Where $n$ is overpotential and $\mathrm{E}, \underline{\mathrm{i}}, \mathrm{R}$ have their usual meaning.

When the free energy of the reaction is large and negative, $E_{C}-E_{A}$ will be a large positive quantity.

We further propose that, the observed difference in the 'switching' potentials (initial potential) for the two units is the result of the differences in the redox character of the working electrodes.

For Example in the conducting polymers the fraction $\mathrm{Q}_{\text {faradaic }} / \mathrm{Q}_{\text {double layer }}$ and capacitive currents $\left(\mathrm{i}_{\mathrm{c}}\right)$ vary with the $\mathrm{pH}$ of the electrolyte media. The net effect of these redox changes in polyaniline modified electrode 'mimmicks' that of 'polarization' in ordinary dry cells.

This assertion is supported by the observation that, when the oxidative charge of the last cycle in the polyaniline was computed and plotted as a function of $\Delta \mathrm{E}_{\mathrm{i}}$, we observe that $\Delta \mathrm{E}_{\mathrm{i}}$ varies with the oxidative charge. See Figure 6.

This observation is not surprising and can be accounted for / or explained by the Nernst equation for reversible systems as follows:

$$
\begin{aligned}
& \mathrm{E}=\mathrm{E}^{\mathrm{o}}-\frac{\mathrm{RT}}{\mathrm{nF}} \ln \frac{\mathrm{C}_{\mathrm{ox}}}{\mathrm{C}_{\text {red }}} \\
& \text { (Equation 1) } \\
& \Delta \mathrm{E}=\frac{\mathrm{RT}}{\mathrm{nF}} \ln \mathrm{C}
\end{aligned}
$$

where

$\mathrm{C}=\mathrm{C}_{\mathrm{ox}} / \mathrm{C}_{\text {red }}$

Since, $\Gamma$ (surface coverage, $\left.\mathrm{mol} / \mathrm{cm}^{2}\right) \propto \mathrm{C}$

And

$$
\Gamma=\frac{\mathrm{Q}_{\mathrm{ox}}}{\mathrm{nFA}}
$$

(Equation 3)

Therefore,

$$
\Delta \mathrm{E}=\frac{\mathrm{RT}}{\mathrm{nF}} \ln \frac{\mathrm{Q}_{\mathrm{ox}}}{\mathrm{nFA}}
$$

Assume, 


$$
\mathrm{k}=\mathrm{nFA} \quad \text { and } \quad \mathrm{k}^{\prime}=\frac{\mathrm{RT}}{\mathrm{nF}}
$$

Then,

$$
\begin{aligned}
& \Delta \mathrm{E}=\mathrm{k}^{\prime} \ln \frac{\mathrm{Q}_{\mathrm{ox}}}{\mathrm{k}} \\
& \Delta \mathrm{E}=\mathrm{k}^{\prime}\left(\ln \mathrm{Q}_{\mathrm{ox}}-\ln \mathrm{k}\right) \\
& \frac{\Delta \mathrm{E}}{\mathrm{k}^{\prime}}=\ln \mathrm{Q}_{\mathrm{ox}}-\ln \mathrm{k}
\end{aligned}
$$

Therefore,

$$
\frac{\Delta \mathrm{E}}{\mathrm{k}^{\prime}}=\ln \mathrm{Q}_{\mathrm{ox}}-\mathrm{k}^{\prime \prime}
$$

Where,

$$
\mathrm{k}^{\prime \prime}=\ln \mathrm{k}
$$

On rearrangement,

$$
\begin{aligned}
& \frac{\Delta \mathrm{E}}{\mathrm{k}^{\prime}}+\mathrm{k}^{\prime \prime}=\ln \mathrm{Q}_{\mathrm{ox}} \\
& \mathrm{Q}_{\mathrm{ox}}=e^{\left(\frac{\Delta \mathrm{E}}{\mathrm{k}^{\prime}}+\mathrm{k}^{\prime \prime}\right)}
\end{aligned}
$$

Therefore $\Delta \mathrm{E}$ will increase with increasing values of $\mathrm{Q}$.

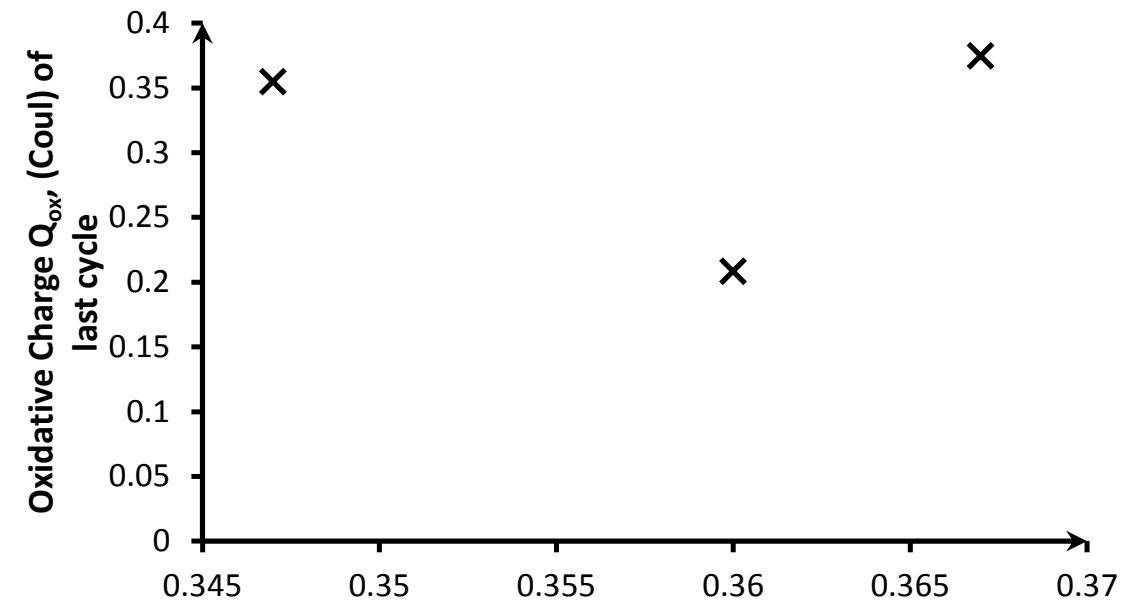

Figure 6: Plot of oxidative charge, $\left(Q_{, o x}\right),($ Coulombs) for the last polyaniline cyclic voltammogram versus potential difference $\Delta \mathbf{E}_{\mathbf{i}}$ for polyaniline.

When the concentration of the sulphuric acid supporting electrolyte was varied i.e., $0.1 \mathrm{M}$, the resultant oxidative charge versus time profile for polyaniline is shown in Figure 7. 


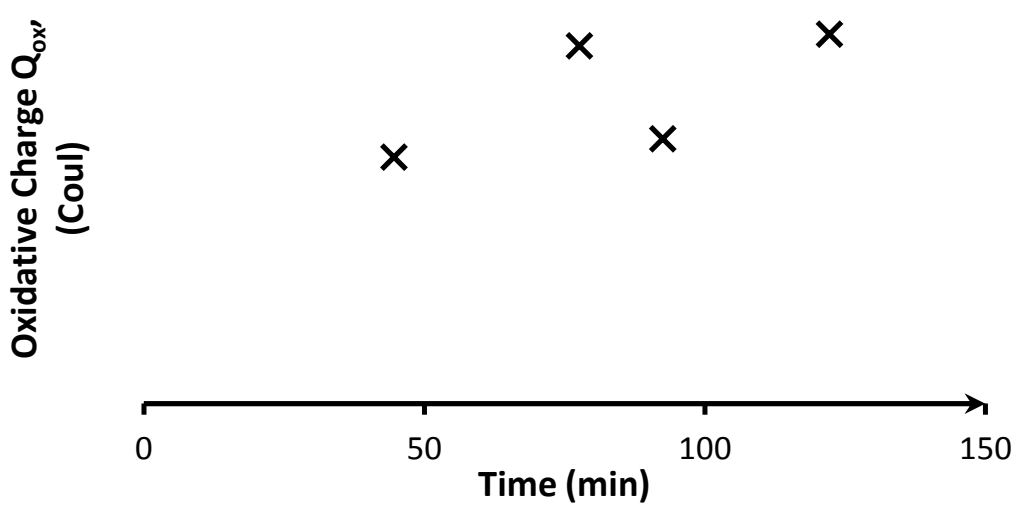

Figure 7: Plot of oxidative charge, $\left(Q_{, o x}\right)$, versus time for polyaniline electrodeposited on a bare carbon electrode in a solution containing $0.1 \mathrm{M}$ aniline and $0.1 \mathrm{M} \mathrm{H}_{2} \mathrm{SO}_{4}$. The potential range was -0.2 to $0.80 \mathrm{~V}$ at a scan rate of $20 \mathrm{mV} / \mathrm{s}$.

The potential versus time profiles for the polyaniline electrode and that of bare carbon are shown in Figures 8 and 9.

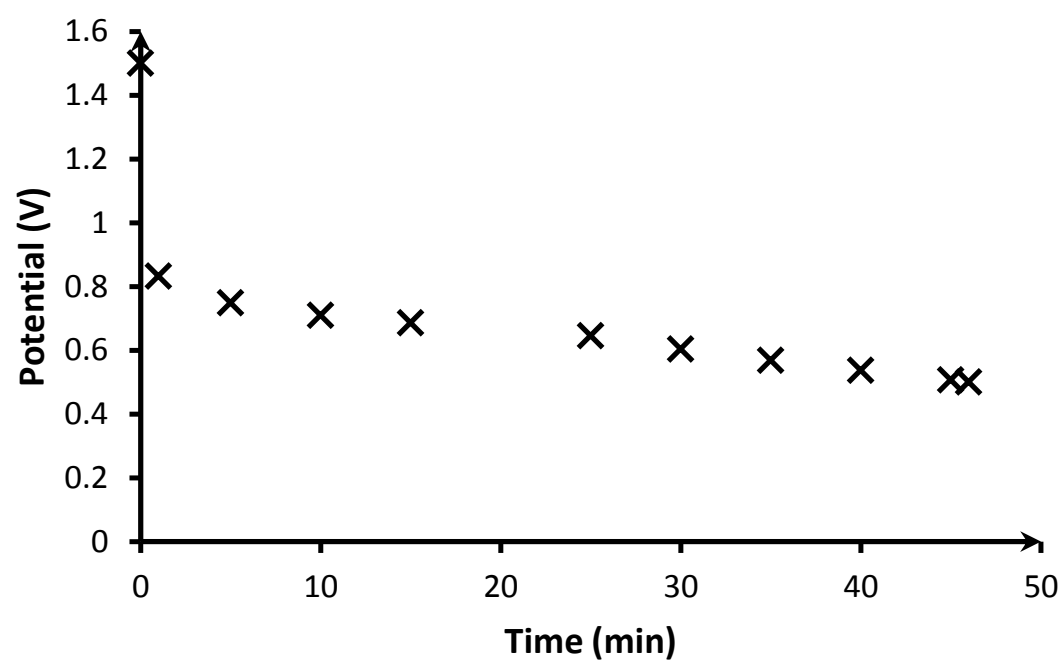

Figure 8: A plot of potential (V) versus time for bare carbon electrode.

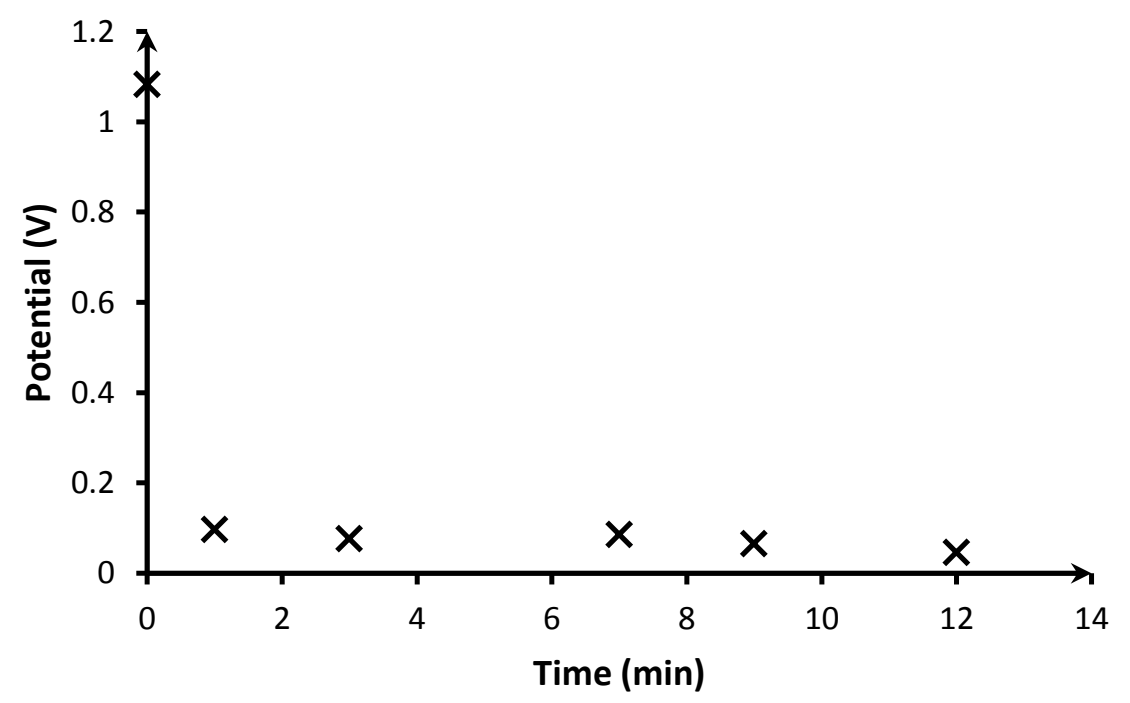

Figure 9. A plot of potential (V) versus time for modified carbon electrode in solution $0.1 \mathrm{M}$ aniline and $0.1 \mathrm{M} \mathrm{H}_{2} \mathrm{SO}_{4}$.

It is observed that, the $\Delta \mathrm{E}_{\mathrm{i}}$ is $71 \mathrm{mV}$, following significant variations in $\mathrm{E}_{\mathrm{L}}(1.500 \mathrm{~V})$ and $\mathrm{E}_{\mathrm{R}}(1.082 \mathrm{~V})$. These observations are expected given that, as already mentioned as the electrolyte $\mathrm{pH}$ increases there is a 
reduction in the faradaic component of the total charge i.e. an increase in the double layer charge and the capacitive currents. Since the potential is proportional to the surface coverage (electroactive) of the polymer, it is therefore suggestive that, as the electrolyte $\mathrm{pH}$ is decreased, this affects the population of electroactive sites in the polymer, hence affecting $\Delta \mathrm{E}_{\mathrm{i}}$ and by extension, $\Delta \mathrm{G}$.

\section{Variation of Concentration of Aniline Monomer:}

In the next set of experiments, the concentration of the aniline monomer was increased to $0.25 \mathrm{M}$. The resultant potential versus time profiles for the bare carbon and polyaniline modified electrode are shown in Figures 10 and 11.

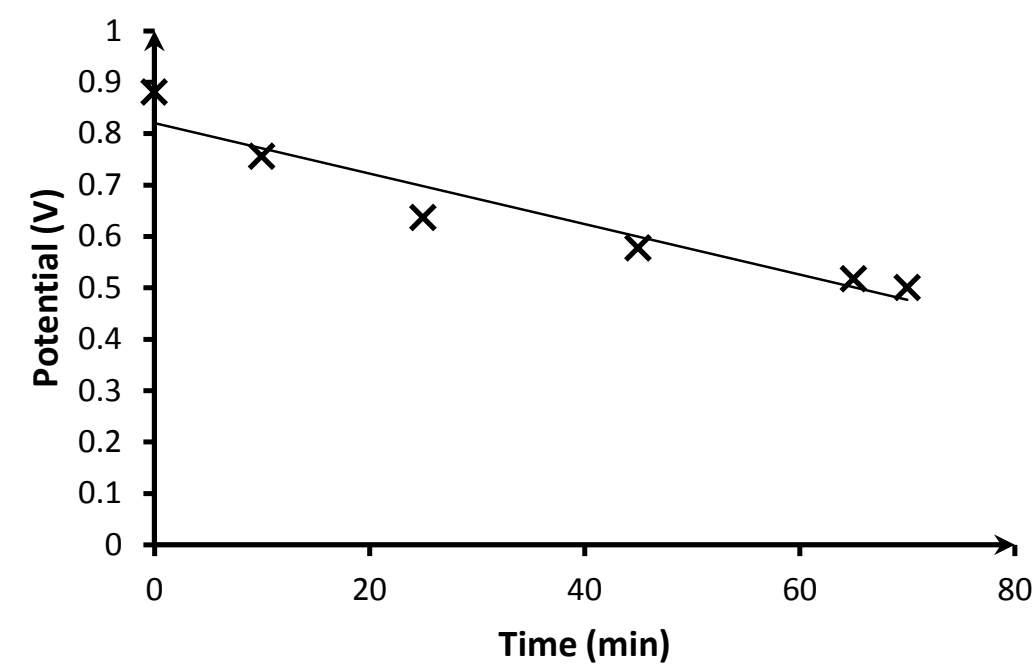

Figure 10: A plot of potential (V) versus time for bare carbon electrode.

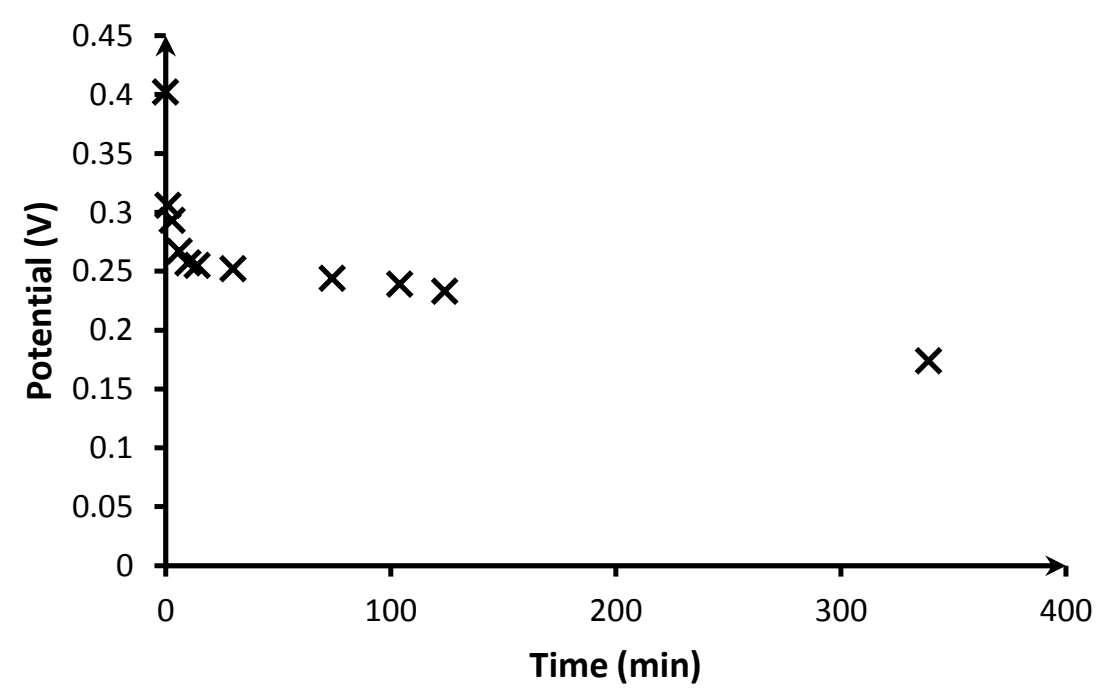

Figure 11: A plot of potential versus time for polyaniline modified carbon electrode electro-generated from a solution containing $0.25 \mathrm{M}$ aniline and $1 \mathrm{M} \mathrm{H}_{2} \mathrm{SO}_{4}$.

The potential versus time profile for the polyaniline modified electrode is shown in Figure 11. Once again the $\Delta \mathrm{E}$ complies with the Nernst equation as already mentioned, see equation 10 .

\section{Polyaniline Modified Electrode in Sodium Chloride -Bentonite Mixture:}

The potential versus time profile for polyaniline modified electrode prepared as already discussed was studied in a sodium chloride-bentonite electrolyte mixture. The $\mathrm{NaCl}$ : Bentonite mixtures were in the following ratios 1:3, 1:2, and 1:1 (mass/mass). The potential versus time profiles is shown in Figure 12. 


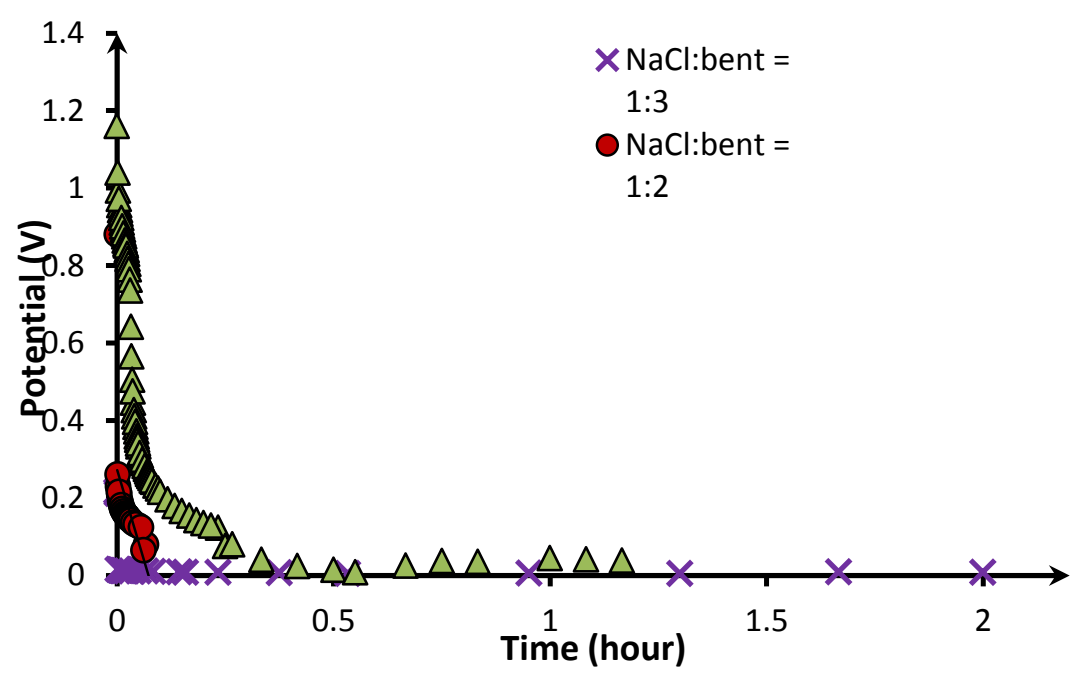

Figure 12: A plot of potential versus time for polyaniline modified electrode in NaCl:Bentonite (mass/mass) - 1:3, 1:2, and 1:1.

We observe that, the rate of change of potential is highest in the case where the ratio of the bentonite and sodium chloride is $1: 1$, followed by $1: 2$ and $1: 3$. We observe that the initial potentials follow the same pattern. Since in the mixture it is the amount of bentonite which is being varied while that of sodium chloride is kept constant, it is therefore, the bentonite which results in the differences in the potential. This observation can be attributed to the fact that, when we have excess bentonite, the concentration of the sodium chloride supporting electrolyte in the matrix is significantly reduced and this is captured/reflected in the reduced voltages.

When the rate of change of potential was plotted as a function of the $\% \mathrm{NaCl}$ and $\%$ Bentonite, the points were a mirror image of one another, even though the percentages were different. It is instructive not to over emphasize this observation, but it is worth noting that, it captures the opposing effect of both substances with respect to the potential. See Figures 13 and 14.

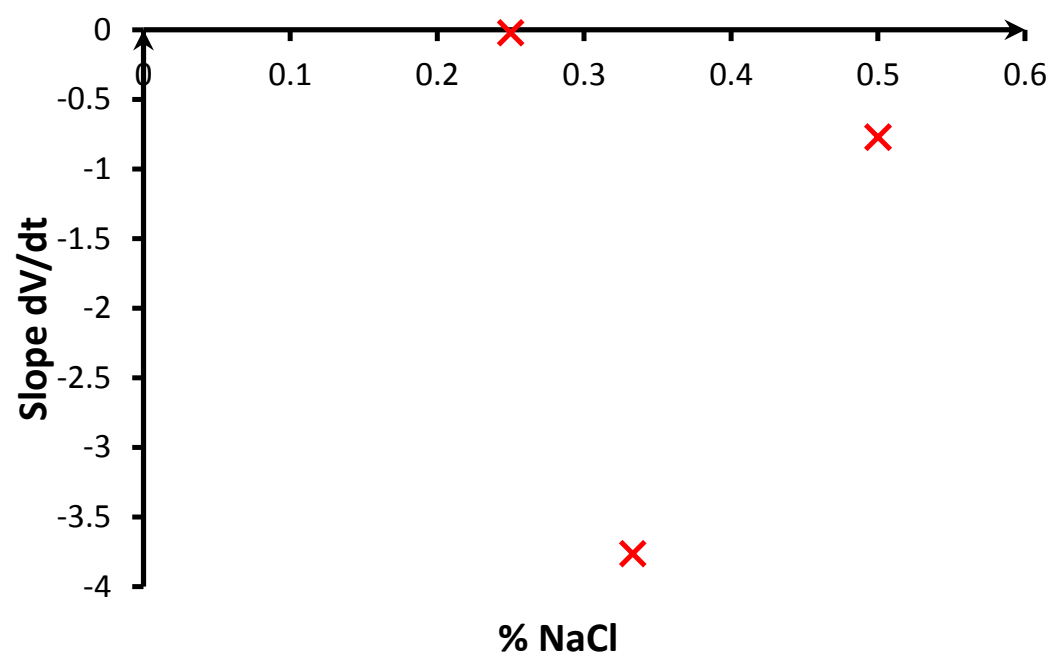

Figure 13: A plot of a slope dV/dt versus \% $\mathrm{NaCl}$. 


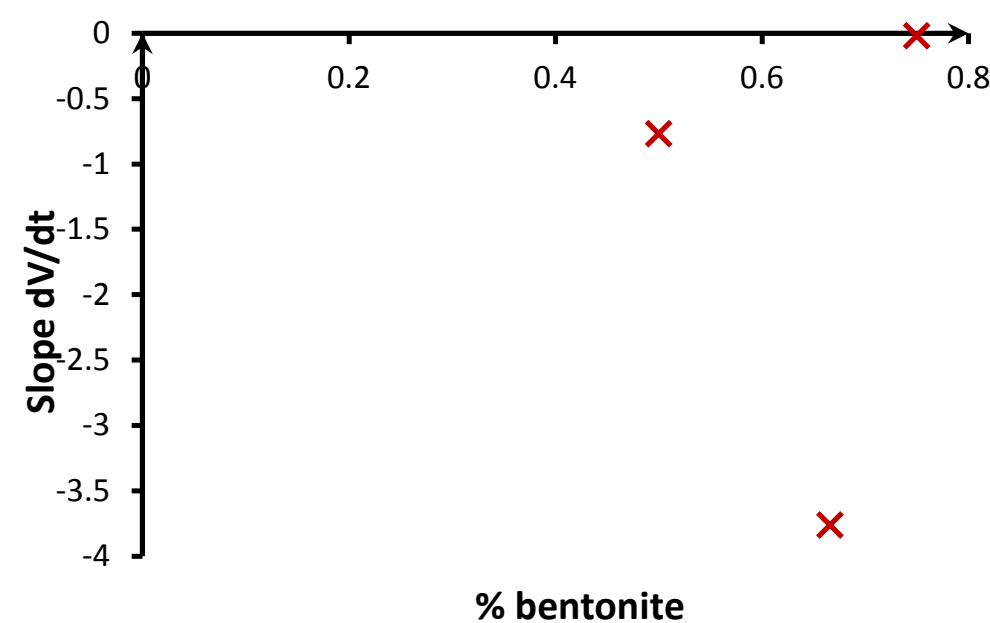

Figure 14: A plot of a slope dV/dt versus \% bentonite.

\section{Hydrocarbon Gel -Bentonite Electrolyte:}

A hydro-carbon gel was mixed with bentonite in the ratio (mass/mass): 1:1 and 1:2. The ratio were then reversed i.e., bentonite: hydrocarbon gel. The above mixtures were thoroughly mixed until a fine colloidal mixture was obtained. To the mixtures obtained was added $\mathrm{NaCl}$. The mass of the $\mathrm{NaCl}$ was always kept equal to that of bentonite in the mixture. A little water was added to the mixture and stirred to form a slurry. Polyaniline modified electrode was prepared as already described in the earlier experiments. The potential versus time discharge profile was then obtained empirically.

Hydrocarbon gel:bentonite ( $1: 1$ ), same amount of $\mathrm{NaCl}$ as the bentonite (water $-17 \mathrm{~g}$, Load - $90.6 \mathrm{ohm}$ )

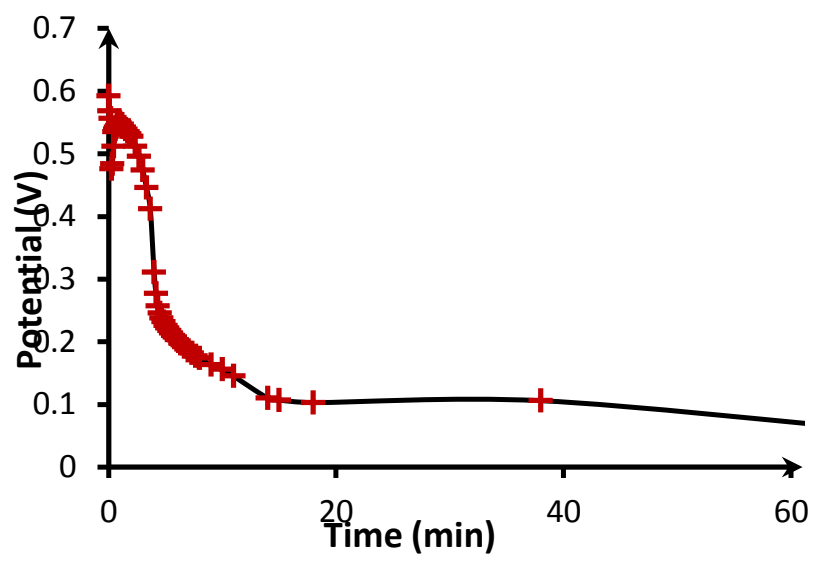

Figure 15 (i): A plot of potential versus time. The electrolyte mixture of hydrocarbon gel :bentonite (1:1). Same amount of $\mathrm{NaCl}$ as the bentonite.

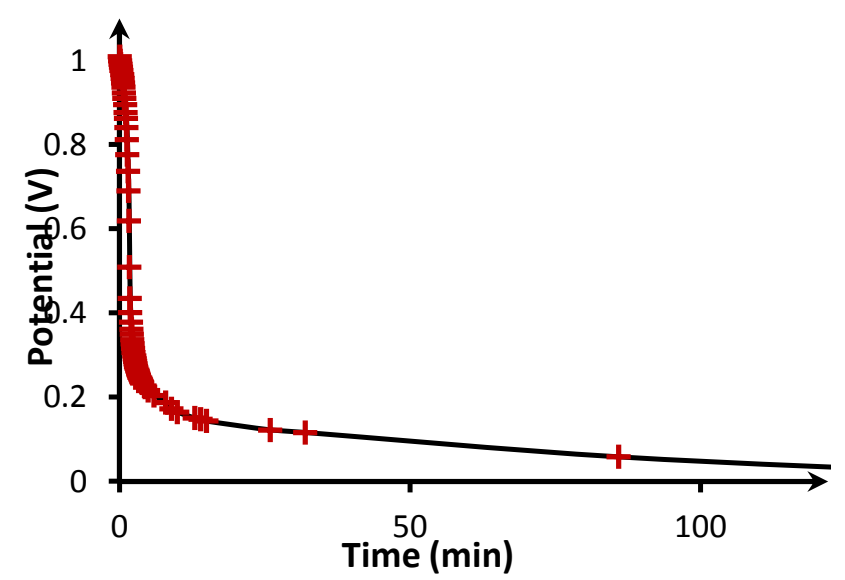

Figure 15(ii): A plot of potential (V) versus time (min). Hydrocarbon gel:bentonite (1:2), same amount $\mathrm{NaCl}$ as bentonite, water $-\mathbf{2 7} \mathrm{g}$. 
From Figures 15(i) and 15(ii) we observe that the discharge decay profile rate in the case of hydrocarbon gel-bentonite mixture is much reduced then in the absence of hydrocarbon gel.

It is also observed that there is no complete discharge in the hydrocarbon gel-bentonite electrolyte mixture i.e., $\left(\mathrm{E}^{\mathrm{min}} \sim 0.08 \mathrm{~V}\right)$

This differences in the discharge profile is probably as a result of improved contact between the electrode and the electrolyte due the presence of hydrocarbon gel. The electrolyte media appear to facilitate the faradaic processes accompanying the redox process in polyaniline i.e., efficient transport of dopant ions.

When the ratio of hydrocarbon gel:bentonite was reversed i.e., 2:1 (see Figure 16), the potential -time profile decay differ significantly from the 1:2 case. This a pointer to the very important role played by the hydrocarbon gel in improving contact surface area between the electrode and the electrolyte and also the migration of supporting electrolyte/dopant ions in the system.

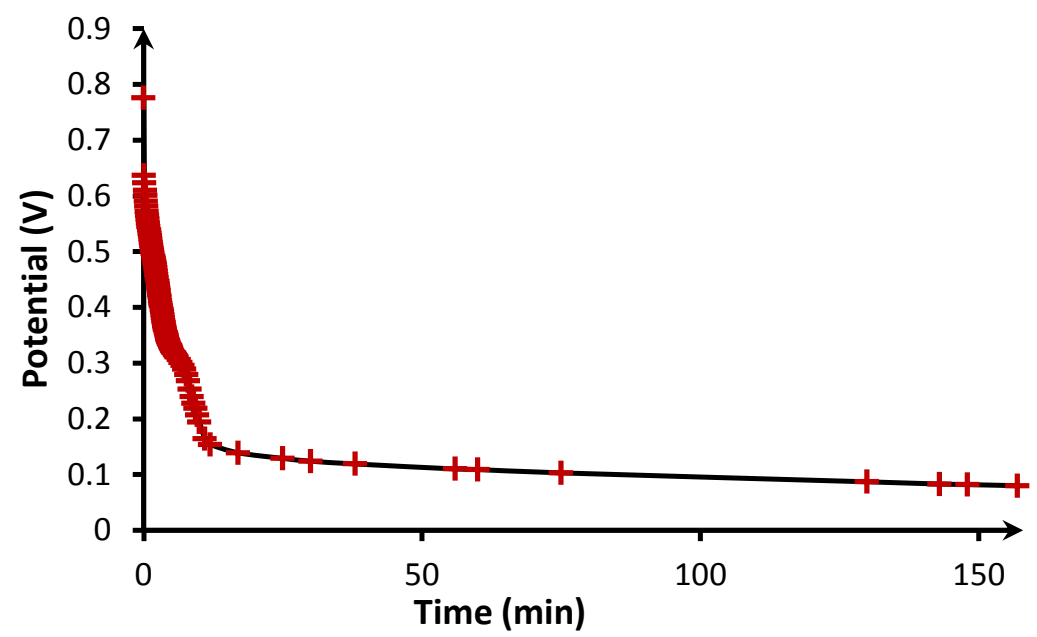

Figure 16: A plot of potential versus time. The electrolyte mixture of hydrocarbon gel: bentonite 2:1.

\section{Same amount of $\mathrm{NaCl}$ as the bentonite.}

Further Analysis Using Other Ratios of Hydrocarbon Gel: Bentonite in the Presence of Water and Sodium Chloride

To further assess the effect of hydrocarbon gel, experiments were conducted using the following ratios of hydrocarbon gel:bentonite $3: 1,3.5: 1,4: 1,5: 2$. In all cases the amount of $\mathrm{NaCl}$ was kept equal to that of bentonite in each experiment. All the prepared mixtures were kept for 72 hours to allow ion exchange to take place. The difference in the initial potential values to that of first potential reading on loading for the various ratios are shown in Figure 17.

From the results it is apparent that, as the mass of the hydrocarbon gel (HC) increases there is a gradual increase in $\Delta \mathrm{V}$.

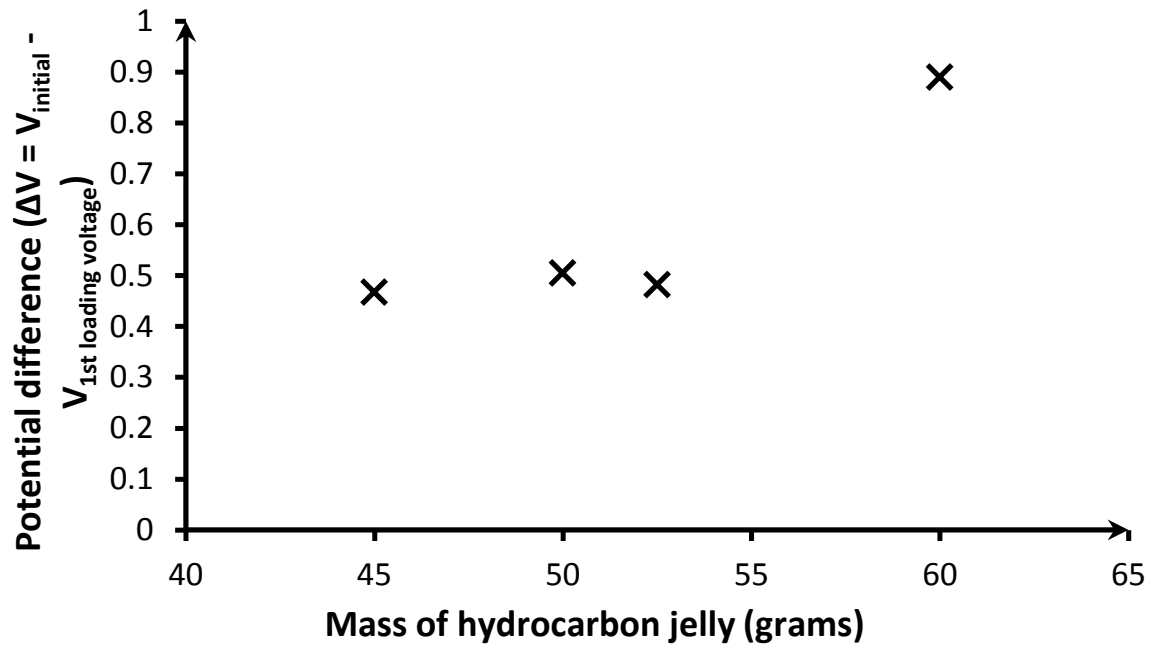

Figure 17: A plot of potential difference $(\Delta E)$ versus mass of hydrocarbon gel (grams). The electrolyte mixture of hydrocarbon gel: bentonite 3:1, 3.5:1, 4:1, 5:2. Amount of $\mathrm{NaCl}$ is equal to that of bentonite. 
The resultant potential versus time profiles are shown in Figures 18(i) - (iv).

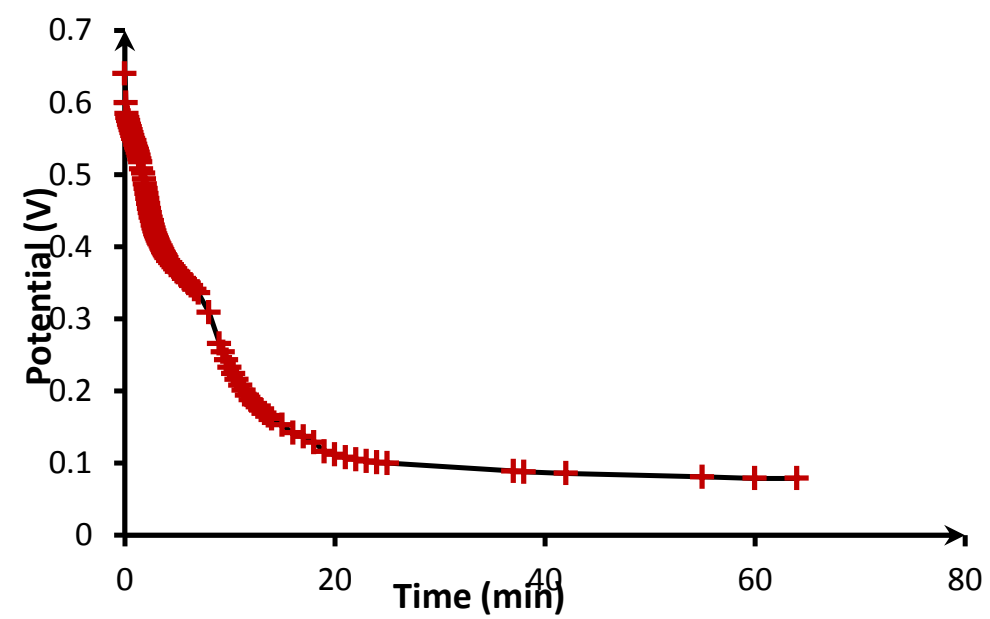

Figure 18(i): A plot of potential versus time for 3:1electrolyte mixture.

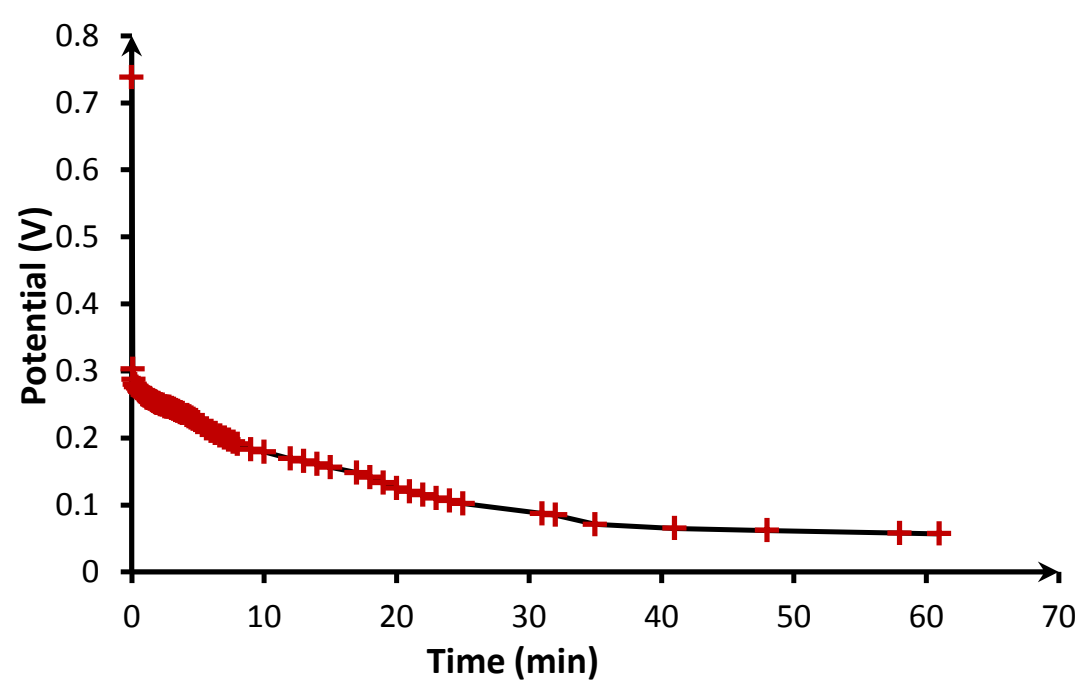

Figure 18(ii): A plot of potential versus time for 3.5:1electrolyte mixture.

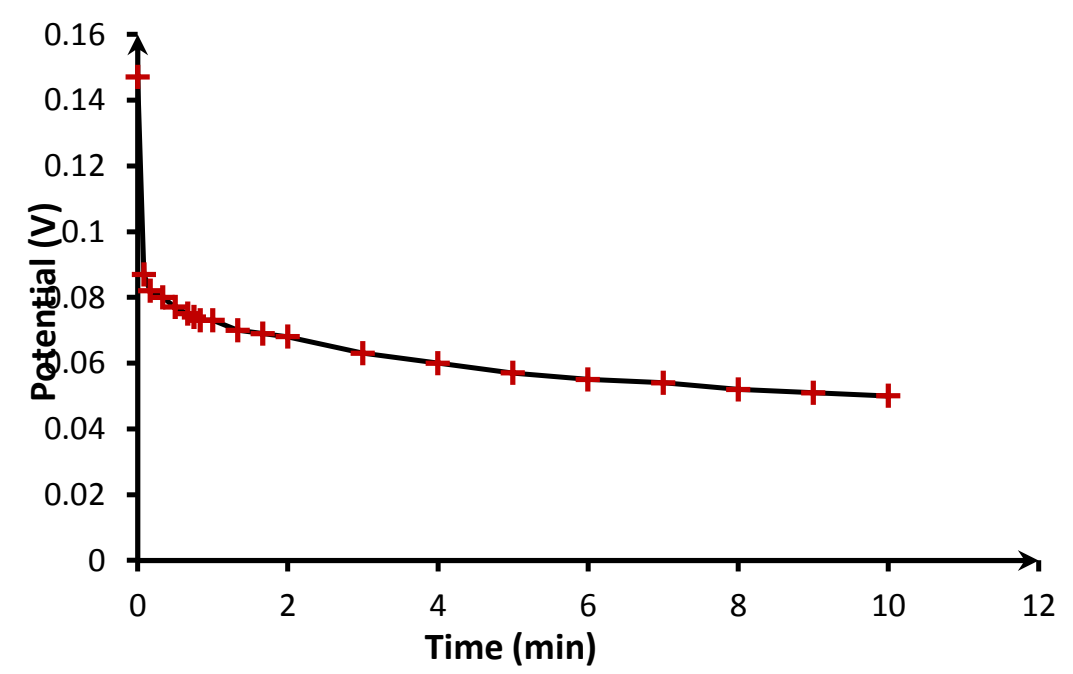

Figure 18(iii): A plot of potential versus time for 4:1electrolyte mixture. 


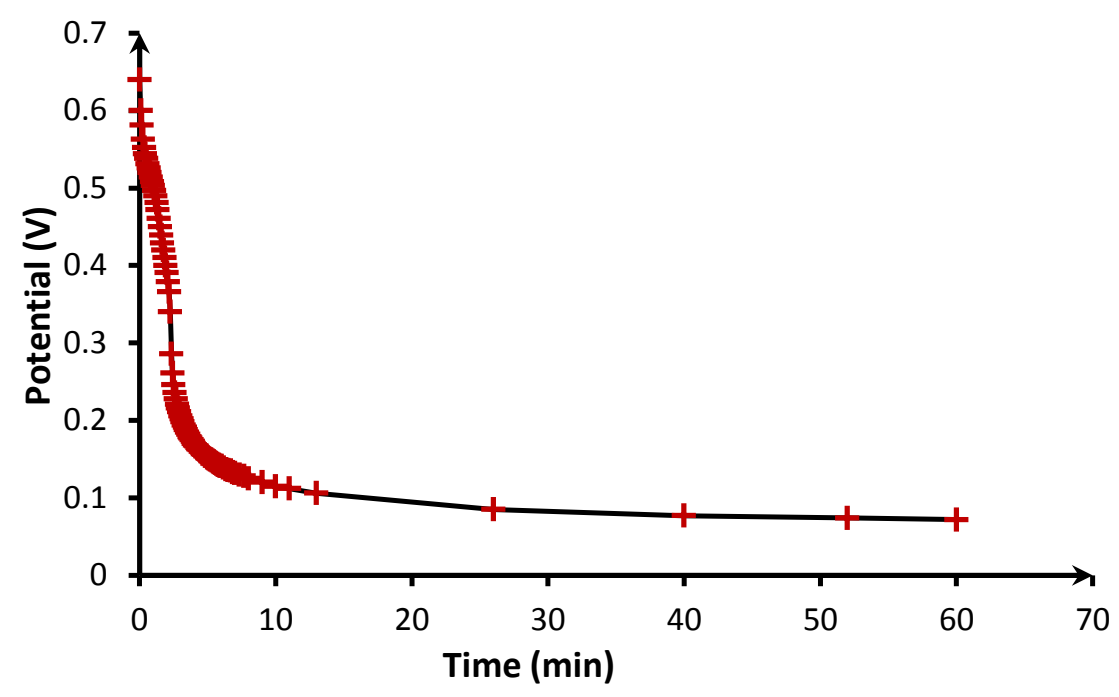

Figure 18(iv): A plot of potential versus time for 5:2 electrolyte mixture.

We observe that, in all the cases of hydrocarbon:bentonite gel there is no total decay of the energy unit. The rate of change of potential/or discharge on loading decreases in the order 3:1, 3.5:1, 4:1. It appears that as the amount of hydrocarbon gel increases, the Gibbs free energy change $(\Delta \mathrm{G})$ approaches zero, hence a balance in the discharge/re-charge redox processes in the energy unit.

From the potential -time profiles, decay profiles for the various ratios of hydrocarbon gel:bentonite was computed to establish the times at which the potential was $3 / 4,1 / 2$ and $1 / 3$ of the initial potential $\mathrm{V}_{\mathrm{o}}$.

The profiles for the 3:1 and 5:2 ratio are shown in Figures 19 (i)- (ii ). It was observed that, the decay is exponential for the 3:1,3.5: 1 and 4:1 case but linear for the 5:2 case.

In the case of exponential decay the discharge profile can therefore be represented as:

$\mathrm{V}_{\mathrm{o}}=\mathrm{V}_{\mathrm{t}} \mathrm{e}^{\mathrm{kt}}$ (Equation 11)

While for the linear 5:2 ratio:

$\mathrm{V}_{\mathrm{t}}=-0.147 \mathrm{t}+0.649$

(Equation 12)

In the linear case, it is apparent that in theory the unit will undergo total decay after sometime i.e., $\mathrm{V}_{\mathrm{t}}=0$, when $\mathrm{t}$ $=0.649 / 0.147$.

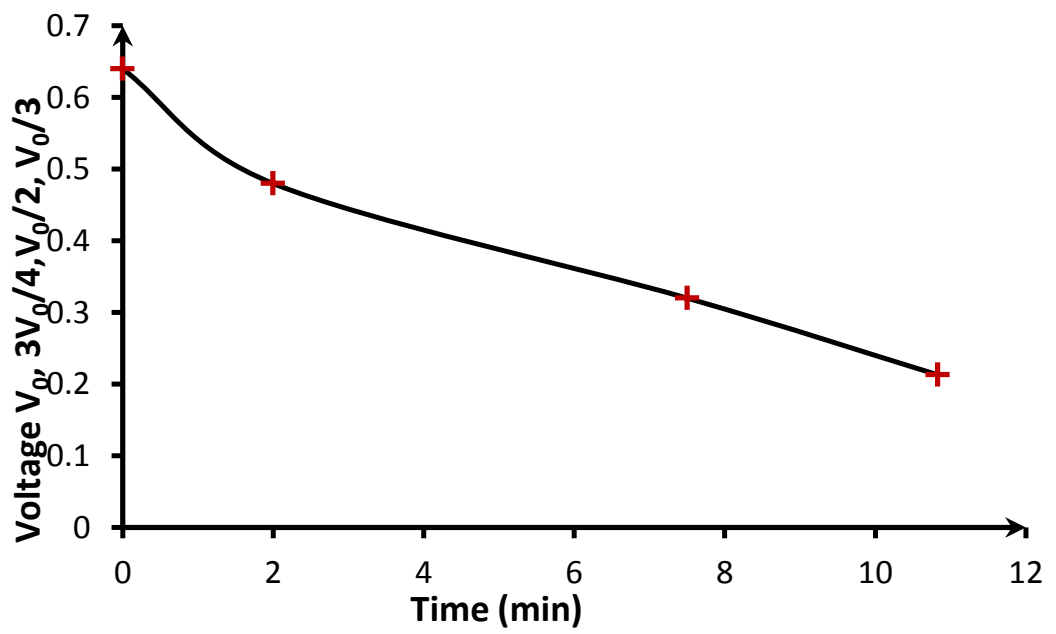

Figure 19(i): A plot of potential $\left(V_{0}, 3 V_{0} / 4, V_{0} / 2, V_{0} / 3\right)$ versus time (min). The electrolyte mixture of petroleum jelly: bentonite 3:1. Amount of $\mathrm{NaCl}$ is equal to that of bentonite. 


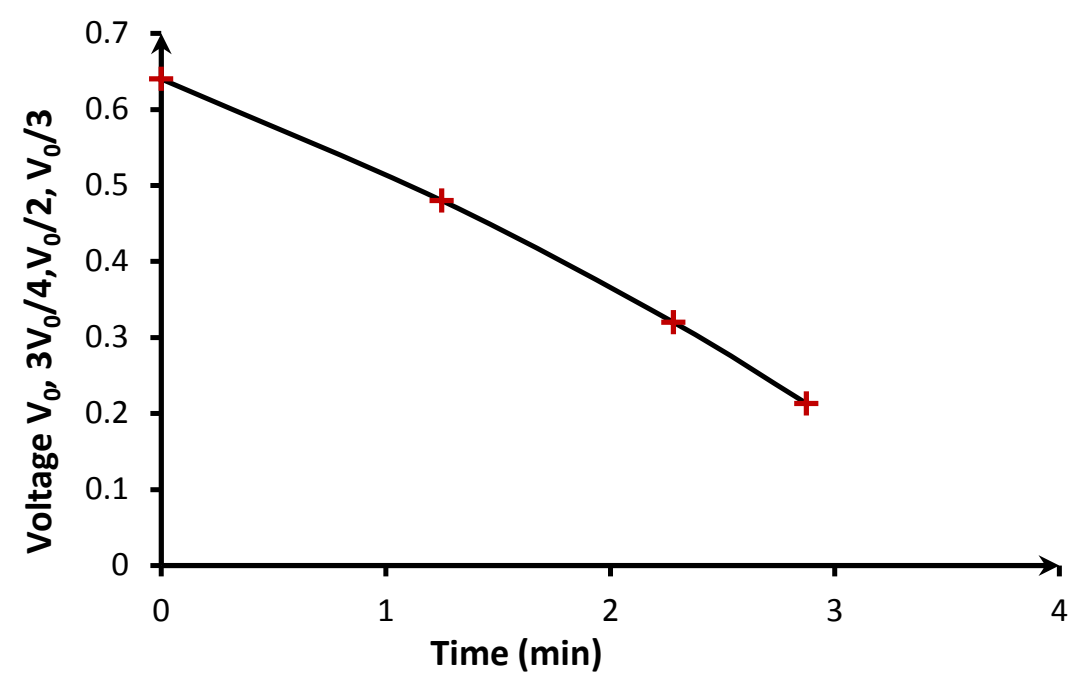

Figure 19 (ii): A plot of potential $\left(V_{0}, 3 V_{0} / 4, V_{0} / 2, V_{0} / 3\right)$ versus time (min). The electrolyte mixture of hydrocarbon gel: bentonite $5: 2$. Amount of $\mathrm{NaCl}$ is equal to that of bentonite.

In some of the energy units, it was observed that, there is an increase in the initial voltage before loading. See Figure 20. This is probably as a result of ingress of dopant ions into the conducting polymer. The increase in the potential - time curve ingress of plateaus off after the $50^{\text {th }}$ minute, probably corresponding to the polymer neutralization of charged sites in the polymer.

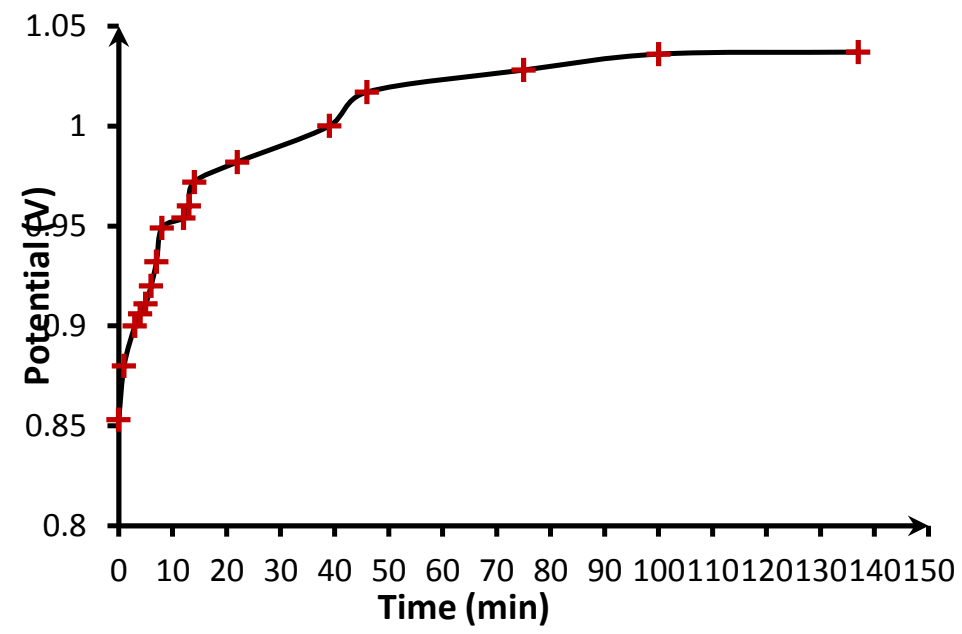

Figure 20: A plot of potential versus time for stabilization of neutral voltage. The electrolyte mixture of hydrocarbon gel: bentonite is $4: 1$.

When $0.1 \mathrm{M} \mathrm{H}_{2} \mathrm{SO}_{4}$ was added to the electrolyte mixture in the energy storage unit and the hydrocarbon gel: bentonite ratio maintained at 2:1 (No water /or sodium chloride), the results obtained from the potential versus time profile (see Figure 21 ), suggests that, increasing the proton $\left(\left[\mathrm{H}^{+}\right]\right) /$and or $\left(\mathrm{SO}_{4}{ }^{2-} / \mathrm{HSO}_{4}{ }^{2-}\right)$ population in the electrolyte mixture has the same effect as that of increasing the hydrocarbon gel in the mixture. This assertion is borne out of the fact that, the rate of change of potential for the 3.5: 1 case is the same as that of 2:1 but with sulphuric acid present. The improvement is probably predominantly the result of the presence of protons which can ingress/ and egress much more efficiently from the polyaniline matrix. The role of sulphate or bisulphate ion vis-à-vis that of chloride ions in sodium chloride is found in the differences in their charge densities. Isomorphous substitution by the protons and sodium cations of the metal ions in the $\mathrm{O}_{\mathrm{h}}$ layer of the clay montmorillonite can also contribute to the observed potential behavior. 


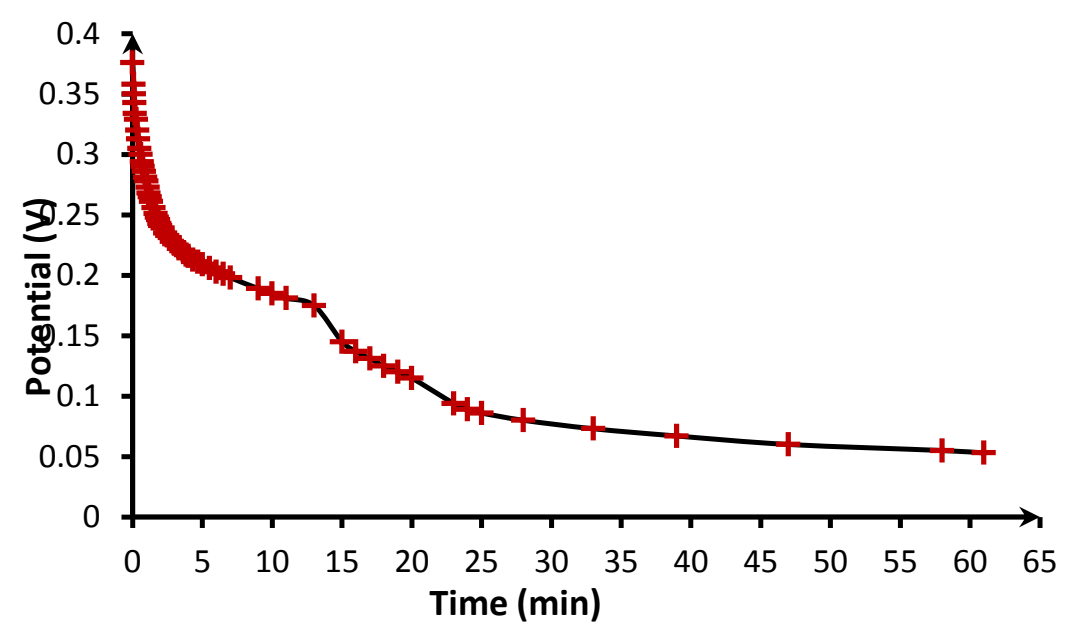

Figure 21: A plot of potential (V) versus time (min). The electrolyte mixture of hydrocarbon gel: bentonite 2:1, and $0.1 \mathrm{M} \mathrm{H}_{2} \mathrm{SO}_{4}$.

\section{Polythiophene Modified Electrodes in the Study of Batteries}

Polythiophene modified electrodes were prepared by cycling the potential of carbon graphite working electrode form $-0.2 \mathrm{~V}$ to $0.85 \mathrm{~V}$ in a solution containing $0.1 \mathrm{M}$ solution of thiophene in $1 \mathrm{M} \mathrm{H}_{2} \mathrm{SO}_{4}$. The scan can rate was $20 \mathrm{mV} / \mathrm{sec}$.

The electrolyte mixture was a slurry containing $\mathrm{NaCl}$ and Bentonite in the ratio of $1: 1$. In this energy unit we observed once again the 'depolarization'/re-charge effect (see Figure 22).

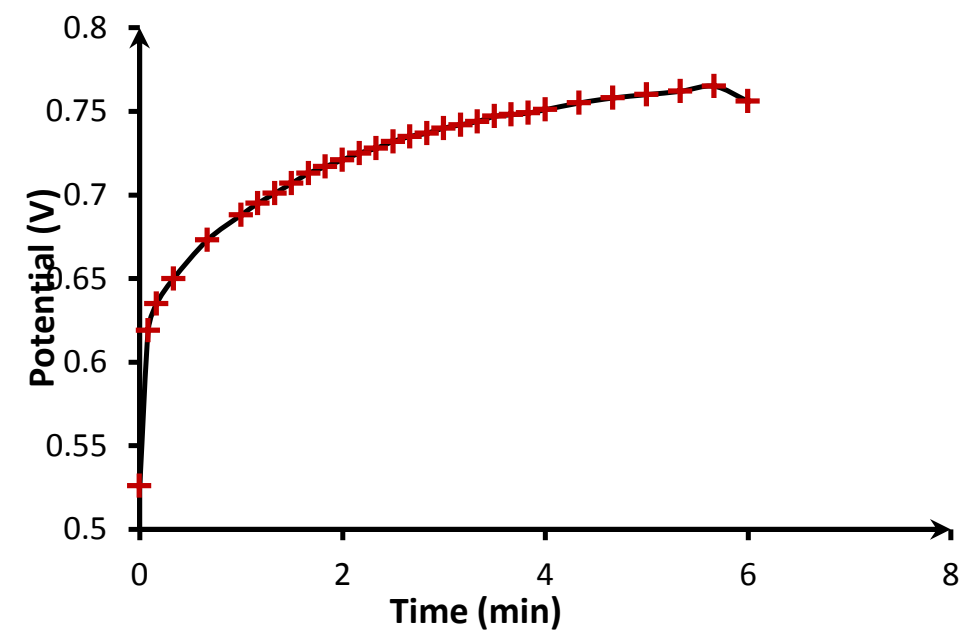

Figure 22: A plot of potential versus time for stabilization of neutral voltage. The electrolyte mixture of NaCl:bentonite 1:1.

The discharge/re-charge profiles in the potential versus time profile (see Figure 23) similarly followed the pattern observed in the case of polyaniline. It is worth mentioning that, the initial potential values for the polythiophene are much lower than that, of polyaniline. This is not surprising given that, polyaniline has much more robust redox properties as compared to polythiophene i.e., well behaved electrochemistry, is easy to synthesize, has reproducible redox characteristics and is a better conductor. 


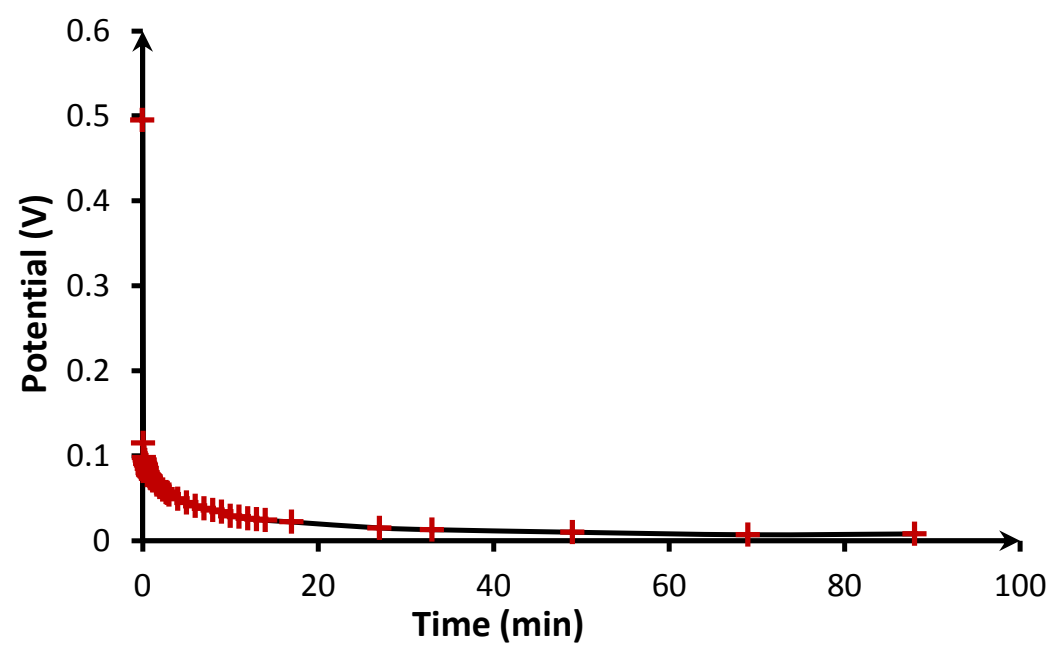

Figure 23: A plot of potential versus time for polythiophene in NaCl:bentonite (1:1).

The decay profile of the polythiophene energy unit yield a linear plot (see Figure 24) with respect to the potential values at $\mathrm{V}_{\mathrm{o}}, 3 / 4 \mathrm{~V}_{\mathrm{o}}, 1 / 2 \mathrm{~V}_{\mathrm{o}}$ and $1 / 3 \mathrm{~V}_{\mathrm{o}}$ with time. The potential decay equation is represented by the equation:

$\mathrm{V}_{\mathrm{t}}=0.075 \mathrm{t}+0.492$.

(Equation 13)

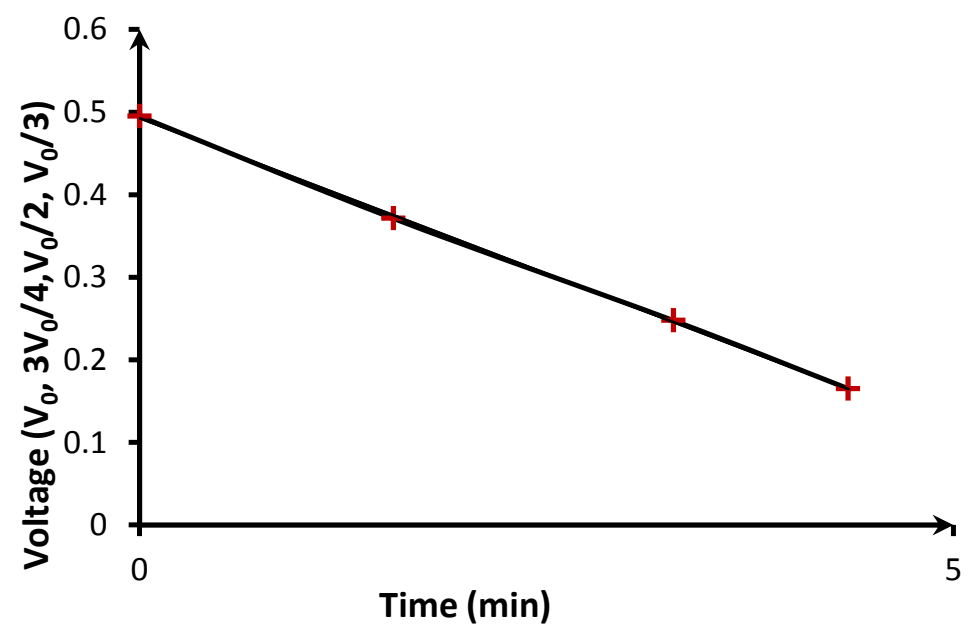

Figure 24: A plot of potential $\left(\mathrm{V}_{0}, 3 \mathrm{~V}_{0} / 4, \mathrm{~V}_{0} / 2, \mathrm{~V}_{0} / 3\right)$ versus time (min). The electrolyte mixture of NaCl:bentonite 1:1.

When the amount of bentonite in the electrolyte is increased by a factor of two (1:2), it is observed that the initial potential is higher by about $510 \mathrm{mV}$. The potential versus time profile, shown in Figure 25, suggests that, the rate of change of potential is not continuous but is phased. This is not surprising since in general polarization at an electrode can result from contributions resulting from charge transfer, nucleation, mass transport and passivation overpotentials. In this case the discontinuity/or formation of a new phase points to nucleation and passivation overpotentials. It worth mentioning that nucleation overpotential is transitory given that, once we have a sufficient number/concentration of new nuclei of the new phase, the overpotential vanishes. 


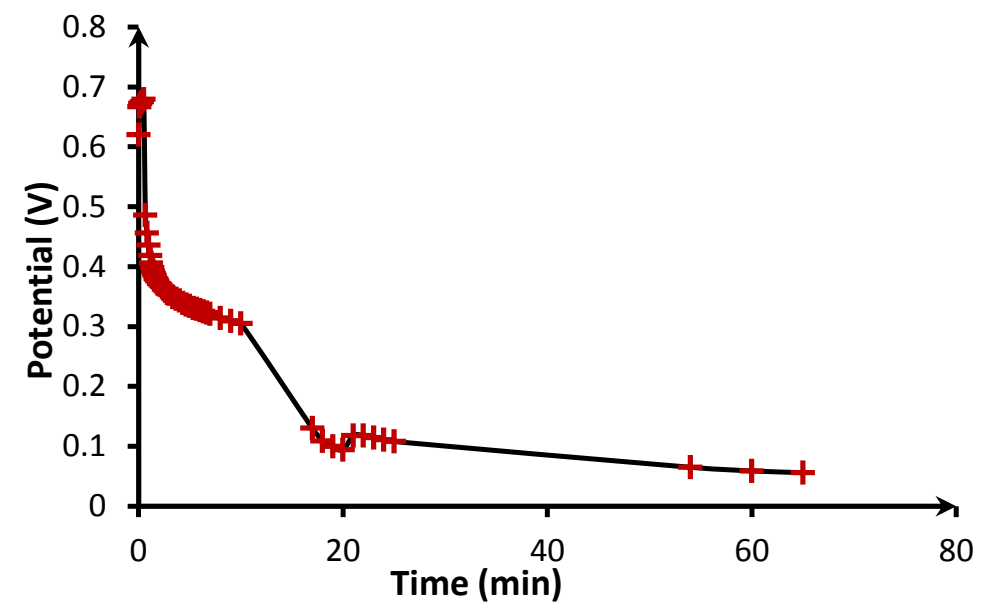

Figure 25: A plot of potential (V) versus time (min). The electrolyte mixture of NaCl:bentonite 1:2.

The decay profile for the electrolyte system $\mathrm{NaCl}$ : Bentonite computed at $\mathrm{V}_{\mathrm{o}}, 3 / 4 \mathrm{~V}_{\mathrm{o}}, 1 / 2 \mathrm{~V}_{\mathrm{o}}$ and $1 / 3 \mathrm{~V}_{\mathrm{o}}$ versus time yielded an exponential plot just as in the case of polyaniline.

When the amount of bentonite was increased three fold i.e., NaCl:bentonite (1:3), the recharge profile for potential versus time displays a maxima and minima (see Figure 26). This profile is probably best described by a trigonometric function, where,

$$
\mathrm{V}_{\mathrm{t}}=\mathrm{V}_{0} \sin \mathrm{kt}
$$

Since discharge/re-charge processes are related to the ingress/egress of dopant ions into the conducting polymer this oscillatory potential versus time curve is probably a pointer to non-isomorphous character of the redox sites in the polymer matrix with respect to accessibility/and or exit by the dopant ions.

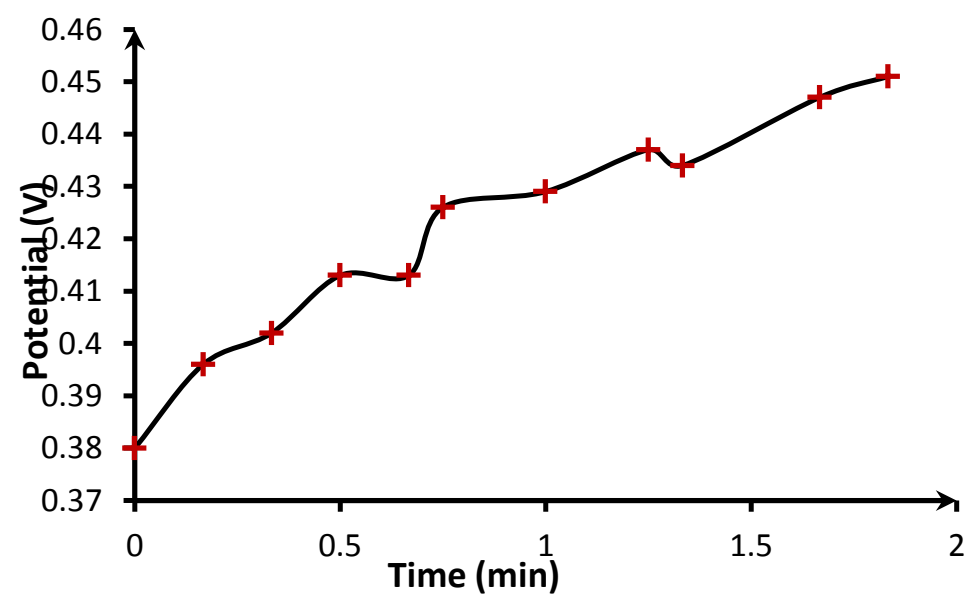

Figure 26: A plot of potential versus time for stabilization of neutral voltage. The electrolyte mixture is NaCl:bentonite 1:3.

\section{Hydrocarbon Gel, Bentonite, $\mathrm{NaCl}$ and Water Electrolyte Mixture:}

When the polythiophene electrode in the energy unit containing hydrocarbon gel: bentonite in the ratio 3:1 (amount of $\mathrm{NaCl}$ same as bentonite) was used, the recharge and discharge potential versus time profiles obtained are shown in Figure 27.

The variation of potential versus time is linear for recharge process, but exponential for discharge. This behavior is similarly to that observed in the polyaniline case. 


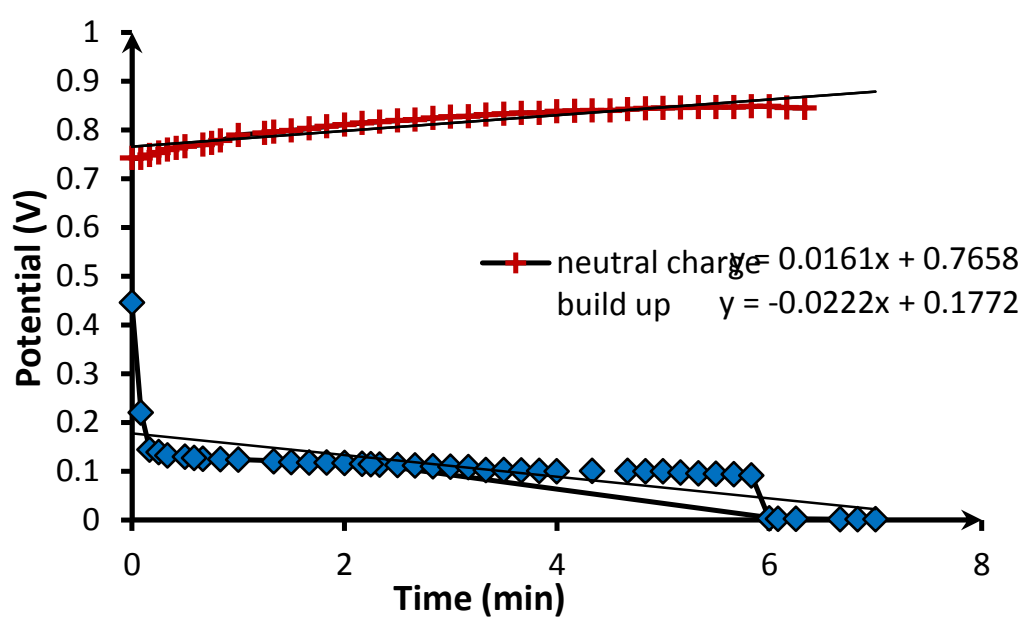

Figure 27: A plot of potential versus time for discharge/re-charge. The electrolyte mixture is hydrocarbon gel:bentonite $=3: 1$.

Capacity and Electric Storage Density of the Energy Storage Unit:

The nominal capacity (C) of the energy storage units were calculated from the expression:

$$
\mathrm{C}=\mathrm{mnF} / \mathrm{M}
$$

where $\mathrm{m}$ is the weight of the active material and $\mathrm{M}$ is the molar mass of the active material. Capacity is determined by monitoring voltage versus time. The capacity (C) for the 2:1 and the 3:1 hydrocarbon: bentonite units were and the following values obtained:

$\mathrm{C}=1.4 \times 10^{-3} \mathrm{Ah}$, for the $2: 1$ energy unit

$\mathrm{C}=3.5 \times 10^{-4}$ Ah for the 3:1 energy unit

The Electric Storage Density (ESD) i.e., capacity per unit weight, considering only the ratios, for the 2:1 and 3:1 energy units and ignoring the masses of the current collectors, terminals and the case: $\mathrm{ESD}_{2: 1}=4.7 \times 10^{-4} \mathrm{Ah} / \mathrm{g}$

$\mathrm{ESD}_{3: 1}=8.8 \times 10^{-5} \mathrm{Ah} / \mathrm{g}$

\section{Conclusion:}

The energy storage units developed using polyaniline and polythiophene modified carbon graphite electrode have yielded voltage versus time profiles (discharge/recharge), with tremendous improvements being registered in the case of electrolyte mixture consisting of hydrocarbon gel and bentonite.

Attempts have been made to compute the capacity (C) and electric storage density (ESD) of the units. Too much emphasis must not be placed on the $\mathrm{C}$ and ESD values given the gaps in the total understanding of the redox mechanism in conducting polymers, not to mention the uncertainty in determining their molar mass which is fundamental in the computation of $\mathrm{C}$. These are pointers to the need for more research so as to develop these polymers into robust energy storage units.

\section{References:}

[1]. Abrissani C., Bongini A., Mastragostino M., Zanelli A., Barbarella G., Zambianchi M., 1995, Conductive electroactive polymers: intelligent polymer systems, Advanced materials, 7, 57.

[2]. Abruna H.D., Meyer T.J., Murray R.W., Chemical and electrochemical properties of 2,2'-bipyridyl complexes of ruthenium covalently bound to platinum oxide electrodes, Inorg.Chem., 1979, 18, 3233.

[3]. Abruna H.D., Walsh J.L., Meyer T.J., and Murray R.W., 1981, Kinetic applications of chemically modified electrodes. Oxidation, reduction and linkage isomerization of a nitrocomplex of ruthenium attached to a silanized platinum electrode, Inorg. Cem., $\mathbf{2 0}$, 1481-1486.

[4]. Aizawa M., Khan G.F., Shinohara H., and Ikariyama Y., 1996, Voltage-assisted peptidesynthesis in aqueous solution by $\alpha$ chymotrypsin immobilized in polypyrrole matrix, J. Am. Chem .Soc., 118, 1824-1830.

[5]. $\quad$ Alcacer L., 1987, Conducting Polymers, D. Reidel Publishing Company, 20.

[6]. Allara D.L., 1995, Critical issues in applications of self-assembled monolayers, Biosenses, Bioelectronics, 10, 771.

[7]. Anderson J.C., Leaver K.D., Rawlings R.D. and Alexander J.M., 1985, Mareials science, $3^{\text {rd }}$ ed., Van Nostrand Reinhold (International), 378.

[8]. Andrieux C.P., Audebert P., Haipot P., Saveant J.M., 1991, Identification of the first steps of the electrochemical polymerization of pyrroles by means of fast potential step techniques, J. Phys. Chem., 95, 10158. 
[9]. Andrieux C. P., Gonzalez F., Saveant J.M., 1997, Derivatization of Carbon Surfaces by Anodic Oxidation of Arylacetates. Electrochemical Manipulation of the Grafted Films, J. Am. Chem. Soc., 119, 4292.

[10]. Arthur D. E., Jonathan A., Ameh P.O. and Anya C., 2013, A review on the assessment of polymeric materials used as corrosion inhibitor of metals and alloys, International Journal of Industrial Chemistry, 4, 2.

[11]. Ballav N., and Biswas M., 2004, A conducting nanocomposite via intercalative polymerization of thiophene in montmorilonite clay, Synthetic Metals, 142, 309-315.

[12]. Bard A.J. and Faulkner L.R., 1980, Electrochemical methods - Fundamentals and applications, John Wiley, New York, 199.

[13]. Barisci J.N., Andrews M.K., Partridge A.C., Harris P., Wallace G.G., 2002, Preparation of polypyrrole/sulfonated-poly(2,6dimethyl-1,4-phenylene oxide) conducting composites and their electrical properties, Sens. Act. B, 84, 252.

[14]. Baughman R.H., 1996, Conducting polymer artificial muscles, Synthetic Metals, 78(3), 339.

[15]. Killian J. G., B.M.C., Gao F., Poehler T. O., and Searson P. C., 1996, Polypyrrole Composite Electrodes in an All-Polymer Battery System, Journal of Electrochemical Society, 143(3), 936-942.

[16]. MacDiarmid A.G., Estemad S. and Heeger A.J., 1982, Polyacetylene, $(\mathrm{CH})_{\mathrm{x}}$. The prototype conducting polymer. Ann. Rev. Phys. Chem., 33, 443.

[17]. MacDiarmid A., 1990, Conductive Polymers, and Plastic Batteries, Basic Energy Sciences, 57, 58.

[18]. Wang C.Y., A.M.B., Hall S.B., Too C.O., Wallace G.G., 2006, Functionalized polythiophene-coated textile: A new anode material for a flexible battery, Short Communication, Journal of Power Sources, 156, 610- 614. 